УдК 902(470.5)(045)

\title{
Э.А. Савельева
}

\section{ПЕРМСКИЙ МИР В ДРЕВНОСТИ И СРЕДНЕВЕКОВЬЕ В РАБОТАХ Р. Д. ГОЛДИНОЙ}

В ноябре 2021 года Римма Дмитриевна Голдина, доктор исторических наук, професор кафедры истории Удмуртии, археологии и этнологии, директор Института истории и культуры народов Приуралья Удмуртского государственного университета, отмечает свой юбилей. В статье представлены основные итоги исследований выдающегося российского учёного по этногенезу пермских народов.

Ключевые слова: археология, этногенез, прапермская общность, коми-пермяки, коми-зыряне, удмурты.

DOI: 10.35634/2412-9534-2021-31-4-683-693

Римма Дмитриевна Голдина - один из лучших представителей поколения учеников выдающихся российских археологов, чьи работы заложили фундамент дальнейших исследований по финноугорской этнокультурной проблематике. Закончив рядовую сельскую школу в Пермской области с серебряной медалью, она поступила в 1958 г. на исторический факультет Пермского государственного университета им. А. М. Горького. Вероятно, выбор профессии был определён благодаря, прежде всего, Владимиру Антоновичу Оборину, чьи лекции по археологии посчастливилось слушать Римме Голдиной. В годы учебы она ежегодно участвовала в полевых экспедиционных исследованиях под руководством опытных полевиков В. Д. Вечтомова, Ю. А. Полякова, И. С. Поносовой и приобрела немалый опыт поисков и раскопок археологических памятников разных типов и эпох.

В Пермском университете, благодаря её первому учителю - Владимиру Антоновичу Оборину, определилась главная научная проблема, которой Римма Дмитриевна посвятила всю свою жизнь этногенез и этническая история пермских народов. Определяющую роль в её становлении как учёного, профессионала высокого ранга сыграл другой выдающийся российский учёный - Владимир Фёдорович Генинг. В 1962 г. он пригласил студентку Пермского университета Римму Голдину для завершения учёбы в Уральский университет.

В своём автобиографическом очерке «Мой путь в археологию» Римма Дмитриевна описывает свой нелёгкий путь завершения учёбы, когда ей пришлось перелопатить горы литературы, чтобы успешно сдать 7 спецкурсов по археологии. Естественно, она их успешно сдала и, как написала в упомянутом очерке, «начала кое-что понимать не только в полевой археологии, но и в самой науке». Римма Дмитриевна за последний год учебы в Уральском университете, а затем в аспирантуре у В. Ф. Генинга получила блестящую теоретическую подготовку, а затем, в годы работы в Уральской археологической экспедиции столь же успешно освоила методику полевых исследований [11, с. 15-55].

Она участвовала в раскопках археологических памятников разных эпох, различной культурной принадлежности в Зауралье и Западной Сибири. Уже в этот период ярко проявились её природные лидерские, организаторские способности. Даже в первые годы работы ей доверяли руководство большими масштабными работами, в которых участвовали отряды численностью более 100 чел.

В 1971 г. в Ленинградском отделении Института археологии АН СССР она успешно защитила кандидатскую диссертацию на тему «Ломоватовская культура в Верхнем Прикамье». Эта тема по рекомендации В. А. Оборина была избрана Риммой Дмитриевной ещё в годы учёбы в Пермском университете, но выделить время для завершения диссертации при огромной нагрузке, связанной с полевыми исследованиями в Уральской археологической экспедиции, было нелегко. Однако она справилась. Работа Р. Д. Голдиной стала первым обобщающим исследованием, в котором были систематизированы и обобщены материалы раскопок 230 памятников ломоватовской культуры, обосновано их культурное единство, определены территориальные и хронологические рамки культуры, выделены 4 этапа в её развитии, обосновано концептуальное положение о двух компонентах в сложении культуры. Хронологические разработки Р. Д. Голдиной по раннесредневековой ломоватовской культуре стали эталонными в приуральской археологии [7]. 


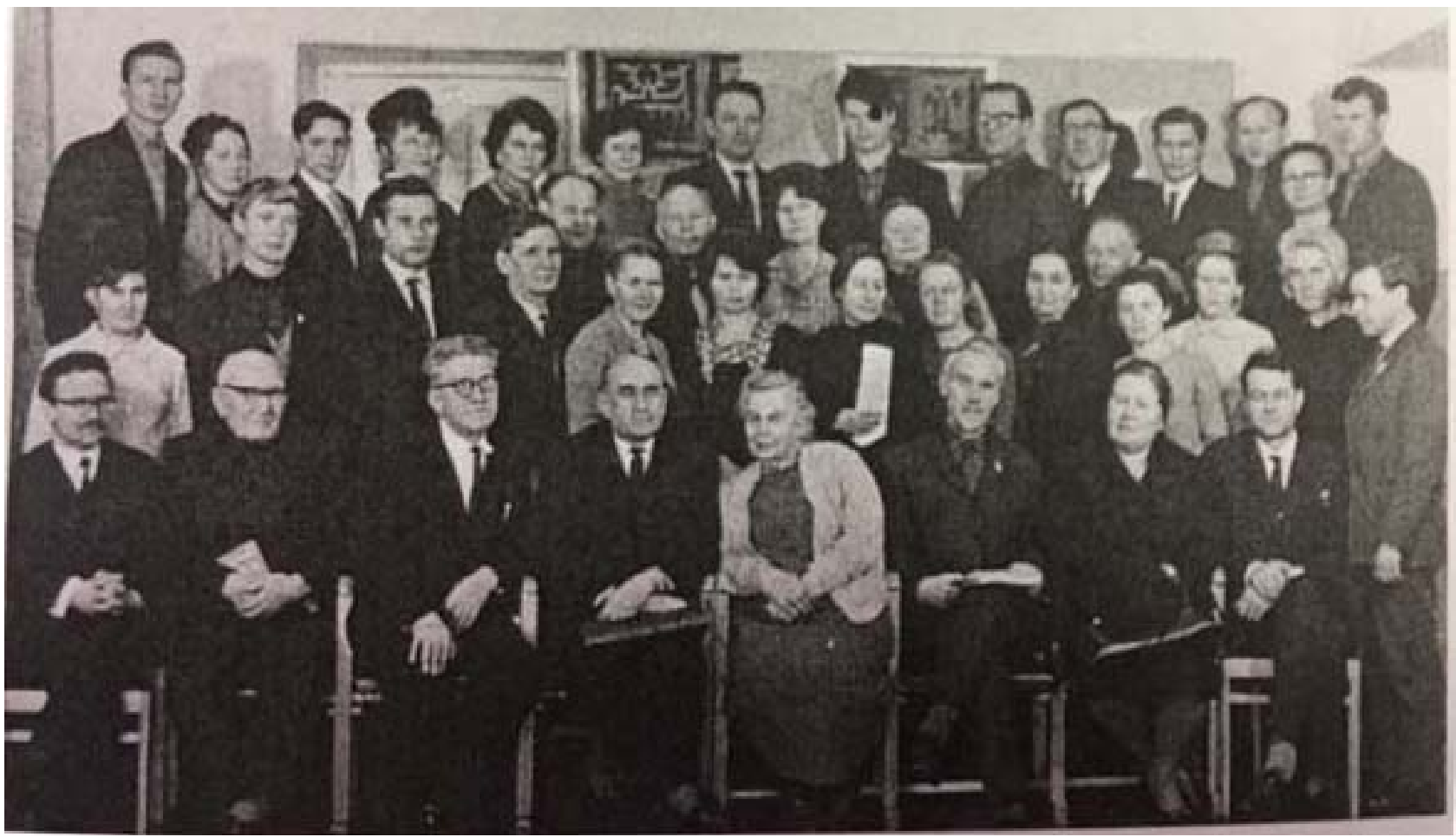

Фото 1. V Уральское археологическое совещание, г. Сыктывкар (1967)

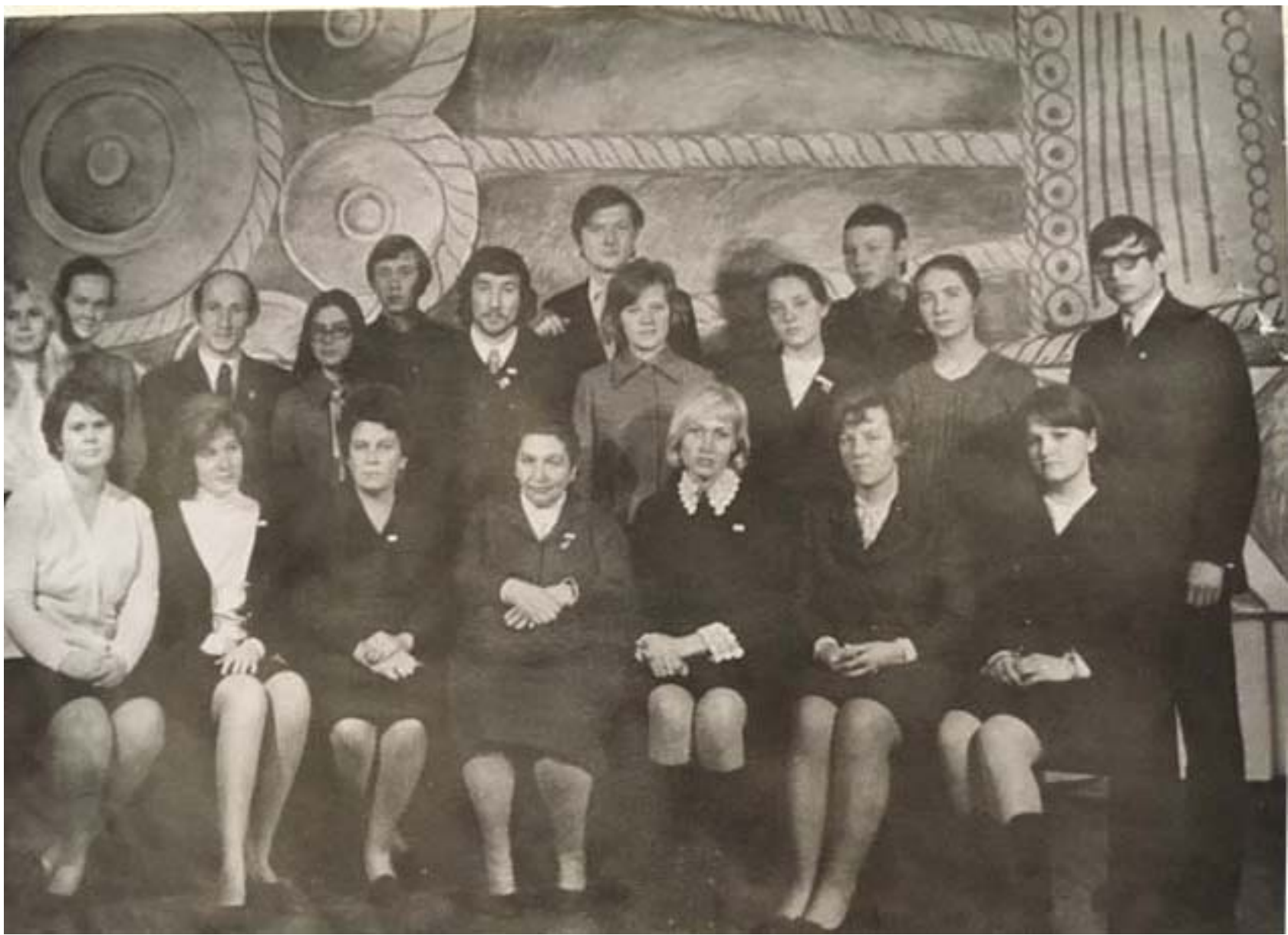

Фото 2. VI Уральская научная студенческая археологическая конференция, г. Ижевск (1974) 
Новый этап в профессиональной деятельности Р. Д. Голдиной начинается в 1972 г., когда ею было принято предложение зав. кафедрой, а затем проректора Удмуртского государственного университета проф. В. Е. Майера принять участие в конкурсе на должность старшего преподавателя для чтения курса лекций «Основы археологии». Причины принятия этого решения изложены Риммой Дмитриевной в её автобиографическом очерке «Мой путь в археологию» [11, с. 38]. К этому времени она приобрела богатый бесценный опыт и в профессиональном, и в научно-организационном плане, которым она была обязана, как мне кажется, прежде всего, В. Ф. Генингу. Он был её Учителем прежде всего в профессиональной сфере: жёстким, требовательным, строгим, с одной стороны; внимательным, доброжелательным, щедрым - с другой. Эти же слова я могла бы адресовать и Римме Дмитриевне. Хотя, возможно, этими качествами она наделена от природы, от родителей, как и талантом, который проявляется не только в её научных публикациях, но и в педагогической деятельности, в блестящих публицистических работах, в целом - в жизни.

Решение переехать в Ижевск стало судьбоносным не только лично для Риммы Дмитриевны, но и для Удмуртского госуниверситета, который стал в 1970-90-е гг. одним из самых крупных научноисследовательских археологических центров, признанных не только в России, но и за рубежом.

В 1973 г. была создана Камско-Вятская археологическая экспедиция, которой за прошедшие годы была обследована обширная территория, включающая Удмуртию, Пермскую и Кировскую области, открыты и раскопаны многие сотни памятников всех хронологических эпох - от мезолита до позднего средневековья. Основные этапы научно-организационной деятельности Р. Д. Голдиной отражены в ряде публикаций её учеников [19, с. 9-16].

Но не могу не выразить восхищения деятельностью Риммы Дмитриевны по подготовке квалифицированных кадров. Ей удалось открыть специализацию по археологии (1974), аспирантуру (1990), кафедру археологии и истории первобытного общества (1991), диссертационный совет по защите кандидатских и докторских диссертаций по археологии и этнографии (1993) и, наконец, Институт истории и культуры народов Приуралья (1993), бессменным директором которого Римма Дмитриевна остаётся. Всё это было сделано практически за 20 лет и стало возможным благодаря выдающимся (именно так) научно-организаторским способностям Р. Д. Голдиной.

Для чтения лекций Риммой Дмитриевной приглашались доктора наук, профессора из ведущих университетов, академических учреждений России. Её ученики обучались в аспирантуре у выдающихся археологов (В. Ф. Генинга, В.В.Седова, Г. А. Фёдорова-Давыдова, А. Н. Кирпичникова, Ю. Л. Щаповой), студенты и выпускники проходили стажировку в зарубежных научных центрах. Естественно, и сама Римма Дмитриевна была блестящим лектором, образованным, эрудированным, способным увлечь археологией своих слушателей. К этому я добавила бы её потрясающую работоспособность. Таких людей в народе называют трудоголиками.

В 1990 г. в МГУ Р. Д. Голдина защитила докторскую диссертацию на тему «Верхнее Прикамье во II половине I тыс. н. э.». Огромный опыт проведения полевых экспедиционных работ способствовал овладению методикой полевых исследований её учениками. Римма Дмитриевна сумела сплотить вокруг себя столь же увлечённых наукой талантливых, трудолюбивых учеников. Среди них 4 доктора и более 30 кандидата наук, которыми опубликованы сотни статей и монографий. Под руководством Р. Д. Голдиной проведены научные конференции и регионального, российского, и международного уровней. Главным результатом её деятельности в Удмуртском университете стало создание научной школы, интеллектуальным лидером которой является Р. Д. Голдина [20]. Одним из главных итогов работы научной школы Р. Д. Голдиной стала реконструкция древней и средневековой истории народов Приуралья.

Р. Д. Голдина в настоящее время является ведущим признанным специалистом по этногенезу и этнической истории пермских финнов. Впервые эта проблема была представлена ею в 1985 г. на VI Международном конгрессе финно-угроведов в Сыктывкаре. Отметим, что к этому времени казанскими археологами (А. Х. Халиков, Е. А. Халикова) была предложена альтернативная признанной ведущими археологами финно-угроведами теория этногенеза пермских финнов. Согласно ей, отделение предков пермских финнов от восточных произошло в I тыс. до н. э. - с выделением от ананьинской общности гляденовских племён; прапермское единство сохранялось около 1,5 тыс. лет - всё гляденовское (III в. до н. э. - V в. н. э.) и ванвиздинское (IV-IX вв. н. э.) время, в IX-X вв. произошёл распад общепермского языка на праудмуртский и пракоми языки, что археологически выражается в выделении вымской культуры перми вычегодской и лузско-вятских могильников древних удмуртов [25, 
c. 5-12]. Ломоватовская, поломская, чепецкая, родановская культуры отнесены к угро- или угротюркским. К древнекоми культуре отнесена вымская. Заселение бассейна р. Камы древними комипермяками, согласно этой концепции, произошло путём переселения племён вымской культуры из бассейна р. Вычегды.

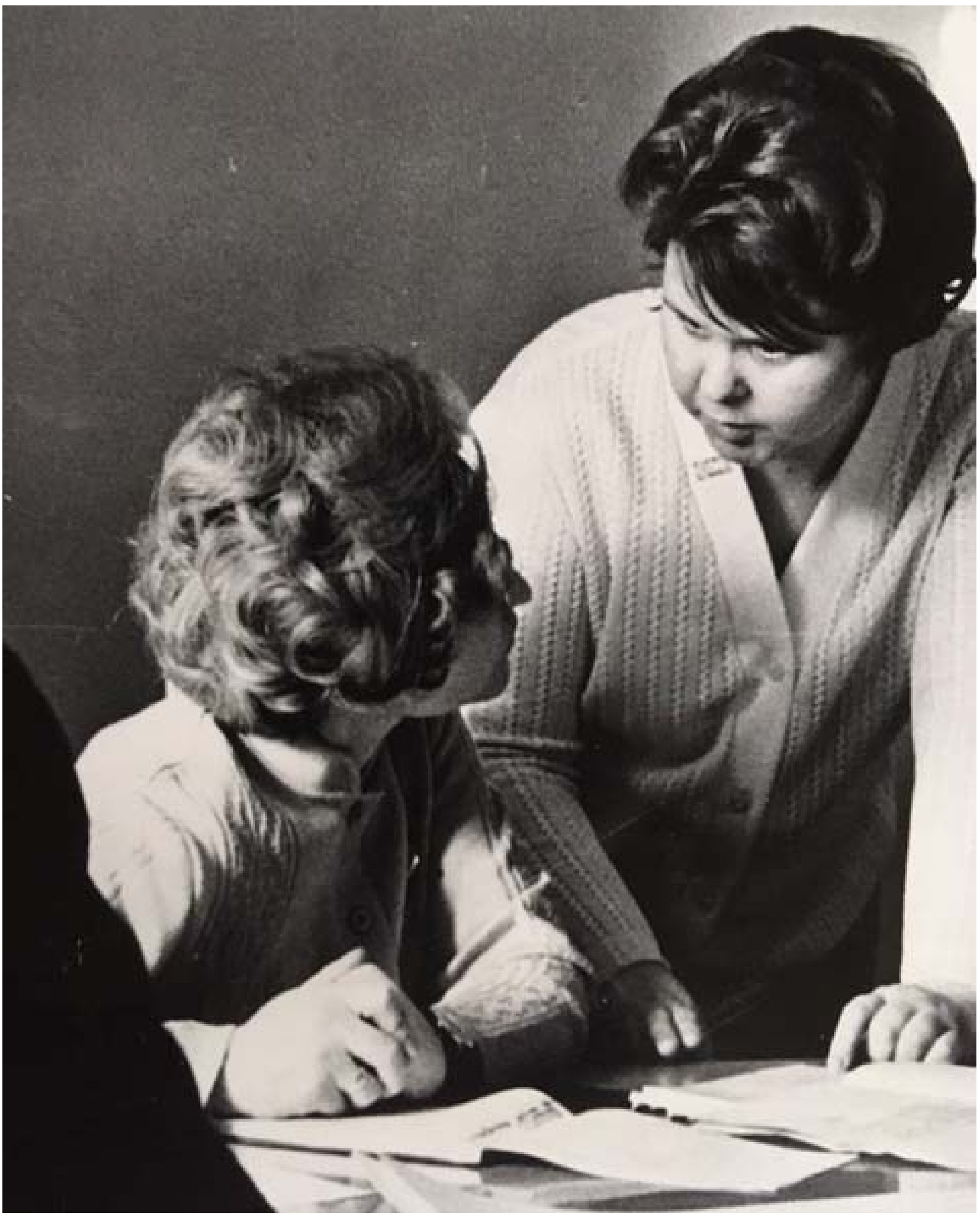

Фото 3. VI Уральская научная студенческая археологическая конференция, г. Ижевск (1974). Э. А. Савельева, Р. Д. Голдина 
Р. Д. Голдина, основываясь на главных концептуальных положениях своих предшественников (А. А. Спицына, А. В. Шмидта, А. П. Смирнова, О. Н. Бадера, В. Ф. Генинга, В. А. Оборина), а также новейших материалах, полученных Камско-Вятской археологической экспедицией и археологами смежных территорий, с одной стороны, убедительно обосновала традиционную точку зрения о формировании пермских финнов в Приуралье, с другой - внесла существенные коррективы в концепцию этнической истории коми-пермяков, коми-зырян и удмуртов. Согласно её концепции, прапермская общность выделилась из восточно-финской в эпоху развитой и финальной бронзы, когда на территории Прикамья, Северного Приуралья фиксируется ряд близких археологических культур, послуживших основой ананьинской этнокультурной общности. Она сопоставляется с прапермской общностью, которая в III в. до н. э. делится на пракоми и праудмуртскую. Первая представлена памятниками гляденовской культуры, вторая - пьяноборской общности в двух вариантах - чегандинском и худяковским.

B V в. н. э. в Приуралье появляются пришлые из лесостепных районов Западной Сибири группы населения, этническая принадлежность которых является не совсем ясной. В результате смешения местного и пришлого населения, формируется ряд финно-язычных культур: ванвиздинская, ломоватовская, поломская, неволинкая. Неволинская, поломская, ломоватовская культуры связываются с предками предков коми-пермяков, ванвиздинская - коми-зырян. В VI в. н. э. пракоми-пермяками была освоена вся территория Верхнего Прикамья, правобережья верховьев р. Чепцы. Праудмуртская общность локализована в Удмуртском Прикамье и представлена памятниками верхнеутчанской, в бассейне средней и нижней Вятки - еманаевской культурой. В формировании южных групп древнеудмуртского этноса отмечается влияние различных групп населения, в т. ч. угорского, балтского или славянского и др.

В Х в., согласно этой концепции, формируются 4 культуры: вымская (в бассейне р. Вычегды), сопоставляемая с древними коми-зырянами; родановская (в Верхнем Прикамье); чепецкая (правобережье верхнего течения р. Чепцы) - с древними коми-пермяками. Древнеудмуртскую общность исследователь локализует в Удмуртском Прикамье (чумойтлинская культура) и в бассейне р. Вятки (кочергинская культура). Это, в кратком изложении, - довольно упрощенная схема развития пермских этносов. Р. Д. Голдина отмечает, что в культуре всех трёх пермских этносов прослеживается влияние соседних этнических объединений - угров, индо-иранцев, волжских финнов, тюрков.

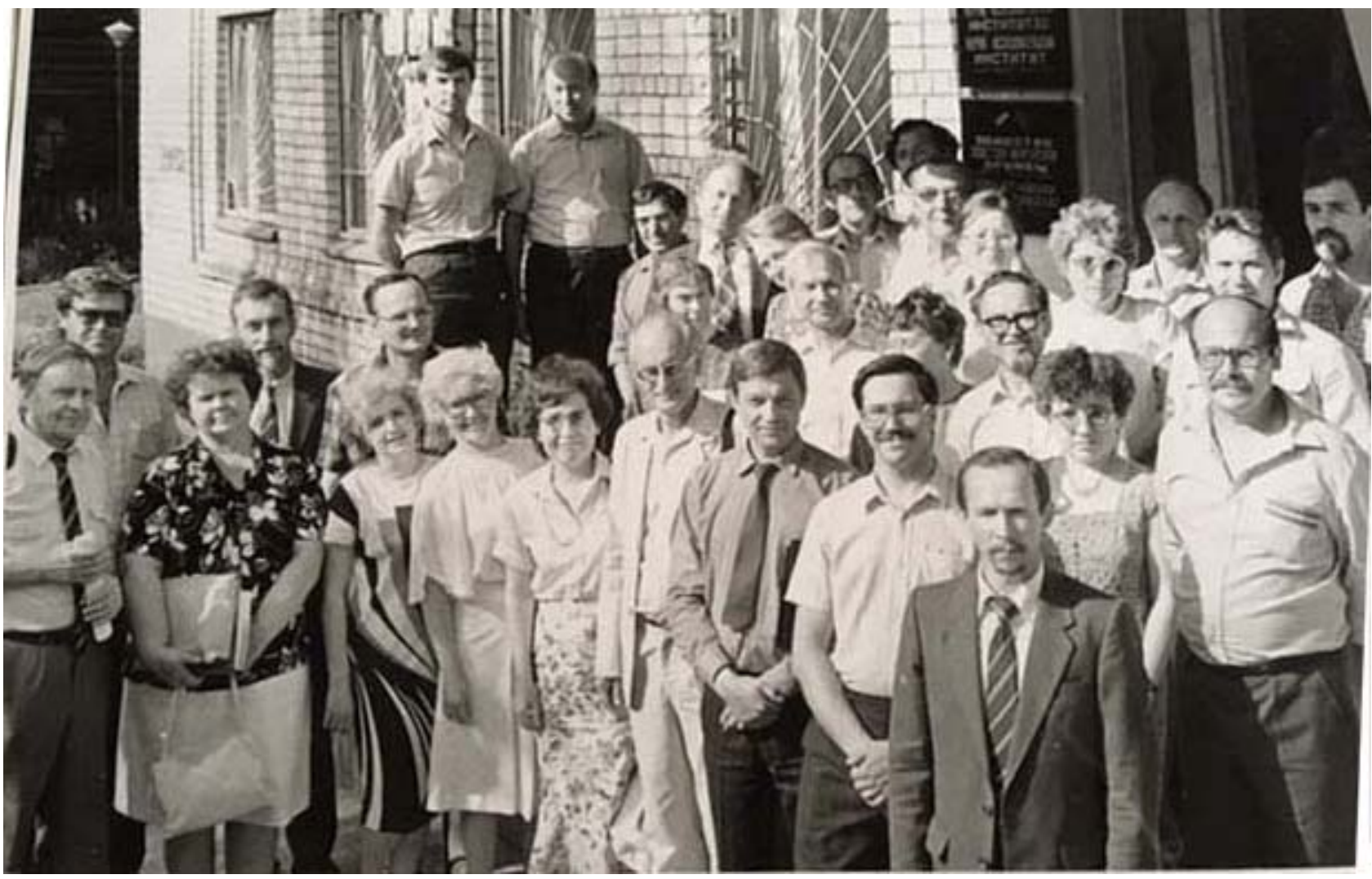

Фото 4. VI Международный конгресс финно-угроведов, г. Сыктывкар (1985) 
Развернутая концепция этнической истории пермских народов в эпоху железа, в значительной мере скорректированная на основе богатейших материалов раскопок археологических памятников на Верхней и Средней Каме, в Сылвенском поречье Камско-Вятской археологической экспедицией, была представлена Р. Д. Голдиной в 1987 г. [8, с. 8-33].

В частности, были выделены особенности формирования различных вариантов этих общностей в различных регионах, обусловленных контактами, миграциями отдельных групп населения. В пьяноборскую общность, кроме чегандинского и худяковского вариантов, включён кара-абызский (северо-западная Башкирия); мазунинские комплексы отнесены к поздней стадии тарасовской (чегандинской) культуры; дана развёрнутая характеристика ломоватовской, неволинской культур; внесены коррективы в проблему генезиса поломской культуры. По мнению Р. Д. Голдиной, поломская культура сложилась на рубеже IV-V вв. н. э. в процессе переселения из верховьев р. Камы ломоватовского населения. C праудмуртской общностью в VI-IX вв. сопоставляются верхнеутчанская культура в Удмуртском Прикамье, бахмутинская на Нижней Белой и еманаевская на Средней и Нижней Вятке. Бахмутинская культура в дальнейшем была ассимилирована пришлыми с юга различными группами населения, верхнеутчанская послужила основой для формирования южных, еманаевская - нескольких групп западных удмуртов. С Х в., согласно этой концепции, фиксируется разделение древнекоми общности на коми-зырянскую и коми-пермяцкую, представленные, соответственно, вымской и родановской культурами. С праудмуртской общностью сопоставляются чепецкая культура в среднем и верхнем течении р. Чепцы, кочергинская - на Нижней и Средней Вятке и чумойтлинская - в Южной Удмуртии, подробно анализируется их генезис, сложный состав и время формирования северных и южных удмуртов [9].

Важное место среди публикаций Р. Д.Голдиной занимает фундаментальная монография «Древняя и средневековая история удмуртского народа» - первая в отечественной историография работа, в которой систематизированы, проанализированы и обобщены данные комплекса источников (археологических, антропологических, лингвистических, этнографических, фольклорных), позволяющих убедительно обосновать основные концептуальные положения по древней и средневековой истории удмуртов [10]. Эта работа по достоинству оценена и удостоена Государственной премии Удмуртской Республики. Её научная значимость, актуальность и востребованность явились основанием для переиздания монографии в 2004 г.

В настоящее время Р. Д.Голдина плодотворно работает в различных направлениях. Ею опубликованы сотни статей, авторские и коллективные монографии. В 2016 г. список её работ составлял 300 единиц, в т. ч. более 10 монографий; за прошедшие неполных 5 лет опубликовано 28 работ, среди которых 4 тома монографии «Тарасовский могильник». Р. Д. Голдиной внесён весомый вклад в изучение эпохи Великого переселения народов в Приуралье. С конца 1990-х гг. ею и коллективом под её руководством разрабатывается проблема взаимодействия культур и этносов Приуралья в древности и средневековье. На основе новейших материалов раскопок Камско-Вятской археологической экспедиции Р. Д. Голдиной впервые высказана гипотеза о новом, западном гото-славянском импульсе в формировании населения эпохи Великого переселения народов в Приуралье в III-IV вв. н. э. Именно с ним Р. Д.Голдина связывает воинские захоронения Тураевского, а также Тарасовского и других могильников III - нач. V вв. н. э. в Нижнем и Среднем Прикамье и на Вятке.

Концепция Р. Д. Голдиной по этногенезу и этнической истории пермских финнов убедительно обоснована и аргументирована на основе комплекса источников. Однако в последние десятилетия возродилась и получила дальнейшее развитие в работах Е. П. Казакова, А. М. Белавина, Н. Б. Крыласовой, В. А. Иванова угорская гипотеза.

Е. П. Казаков к угорским, кроме ломоватовской, относит и ванвиздинскую культуру, которую А. Х. Халиков считал пермской, генетически связанной с вымской. А. М. Белавин, Н. Б. Крыласова, В. А. Иванов к угорским относят поломскую, неволинскую, ломоватовскую и родановскую (на раннем этапе её развития) культуры, не исключая в них финский компонент. С древнекоми общностью, вслед за А. Х. Халиковым, А. М. Белавин и Н. Б. Крыласова соотносят вымскую культуру перми вычегодской, но, в отличие от А. Х. Халикова, они не касаются проблемы этнической принадлежности ванвиздинской культуры.

Появление коми-населения в Пермском Приуралье в XI-XII вв. они связывают с миграцией носителей вымской культуры, «не определяя её истоков, в одном потоке с западно-балтийско-финским населением» [3, с. 99]. Средневековое население Верхнего Прикамья представляется как двухкомпо- 
нентный (угорско-пермский) этнос. Смену угорского «(вмещающего) этноса» пермским А. М. Белавин относит к концу XI-XII вв. [4, с. 11-12].

Блестящий критический анализ угорской концепции Е. П. Казакова дан в одной из публикаций Р. Д. Голдиной [12, с. 89-110]. Развёрнутая критика концепции угорской принадлежности раннесредневековых культур Прикамья представлена в ряде работ Р. Д. Голдиной и других пермских и ижевских археологов, этнографов, лингвистов [12-14].

Исследования археологов Коми, обобщённые результаты которых изложены в коллективной монографии «Археология Республики Коми» (1997), подтверждают основные положения концепции Р. Д. Голдиной о формировании пермских финнов [1].

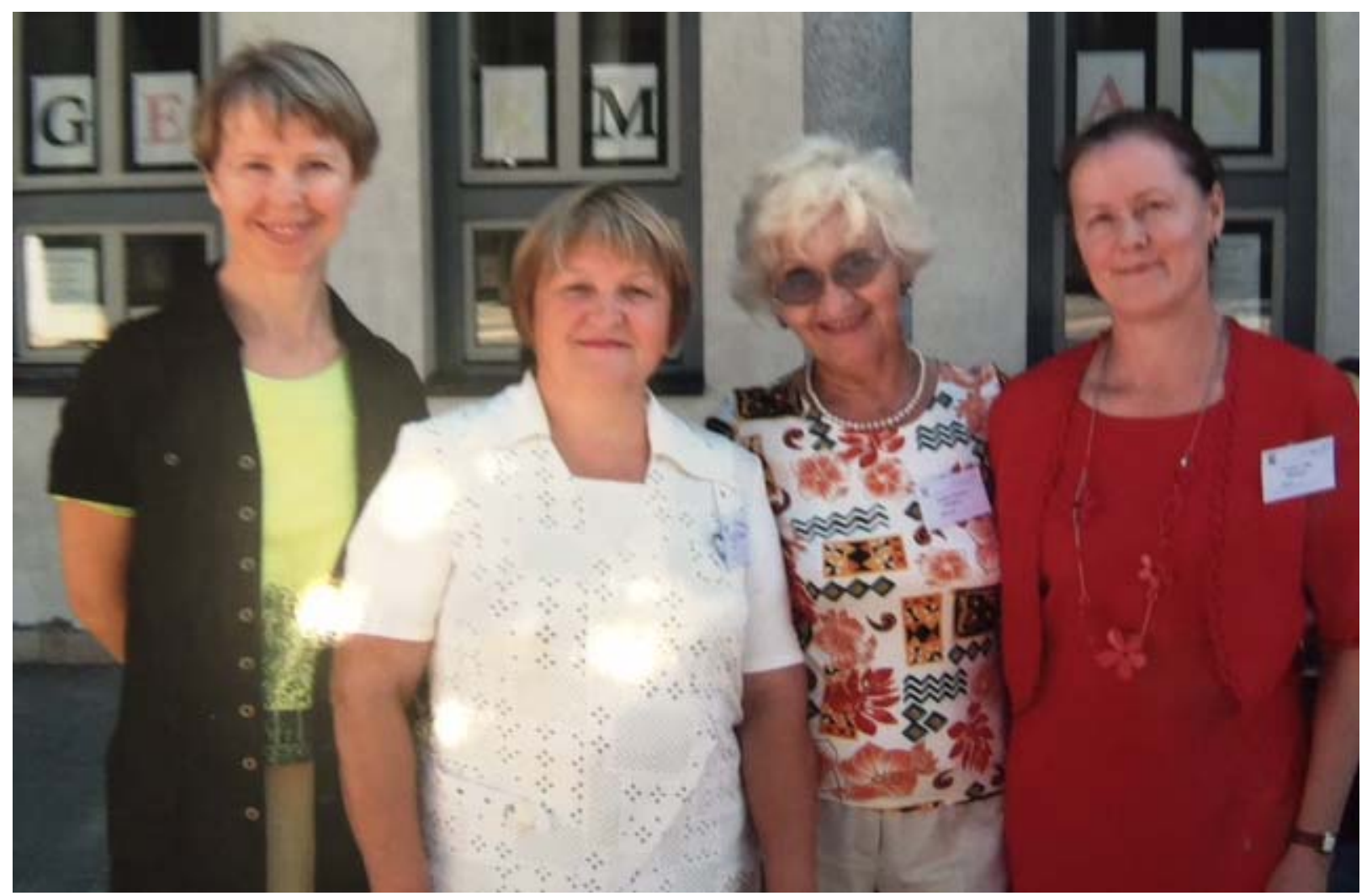

Фото 5. ХІ Международный конгресс финно-угроведов, г. Пилишчаба, Венгрия (2010).

Слева направо: Е. В. Голдина, Т. К. Ютина, Э. А. Савельева, О. А. Казанцева

Территория Европейского Северо-Востока не позднее чем с эпохи энеолита - бронзы входила в одну историко-культурную область с Прикамьем, что не исключает инокультурные компоненты в формировании археологических культур этого региона, обусловленные контактами с соседними племенами (угорскими, самодийскими, западными и др.).

В эпоху раннего железного века Европейский Северо-Восток входит в ананьинскую этнокультурную общность, представленную культурными типами Ласта, Ямашор, Перныый и Чаркабож, выделенными В. И. Канивцом [16, с. 121-147]. Основные концептуальные положения В. И. Канивца получили дальнейшее развитие в работах Л. И. Ашихминой и И. О. Васкула, согласно которым формирование северного варианта ананьинской этнокультурной общности было результатом взаимодействия лебяжской, маклашеевской, ерзовской археологических культур Приуралья и культур с фигурно-штампованной керамикой Западной Сибири и Зауралья [2, с. 331-333].

Об усиливающихся контактах с Прикамьем с середины I тыс. до н. э. свидетельствуют керамические комплексы типа Перный, а также материалы Шиховского могильника на Печоре, исследованного И. О. Васкулом, где найдены однотипные с ананьинскими древностями Волго-Камья украшения, предметы вооружения, культовые изделия, наблюдаются общие элементы в погребальной обрядности [6, с. 7-17]. Как и в Прикамье, на Европейском Северо-Востоке в конце III в. до н. э. куль- 
туры ананьинской этнокультурной общности сменяются гляденовскими [5]. В рамках гляденовской общности И. О. Васкулом выделены две культуры: пиджская в бассейне рр. Печоры и Мезени и джуджыдъягская в бассейне р. Вычегды, сформировавшиеся на основе предшествующих культурных типов ананьинской общности, в которых также проявляется влияние выходцев из Прикамья и Зауралья. Как отмечает И. О. Васкул, этнокультурные связи с культурами Прикамья были постоянными и прочными, что особенно прослеживается по материалам джуджыдъягской культуры. Близость гляденовских древностей Верхнего, Среднего Прикамья и Европейского Северо-Востока объясняется их формированием на базе родственных культур предшествующего периода [5, с. 381].

К эпохе раннего средневековья в бассейне рр. Вычегды и Мезени относится ванвиздинская культура VI-X вв. н. э., истоки которой восходят к культурам гляденовской общности, осложнённой появлением из Прикамья населения, связанного с лесостепными районами Западной Сибири. Аналогичные процессы происходили и в Прикамье. Пришлое население с курганным обрядом погребения было ассимилировано потомками гляденовцев. Ванвиздинская культура явилась основой формирования вымской культуры перми вычегодской. Их генетическая преемственность обоснована в ряде работ, концентрированное выражение которой дано в статье К. С. Королёва и Э. А. Савельевой [18 и др.].

Не вызывает сомнений этническая принадлежность вымской культуры древним коми-зырянам, что находит подтверждение в письменных источниках, в частности, в «Житии Стефана Пермского» [22]. Р. Д. Голдина объединяет памятники ванвиздинской и вымской культур в ванвиздинсковымскую общность, что представляется вполне целесообразным. Она определяет эту общность как периферию пермского мира, формирование и развитие которого в значительной мере определялось его географическим положением и природно-климатическими условиями [12, с. 107].

Родство и близость родановской и вымской археологических культур проявляется, прежде всего, в традиционных элементах материальной и духовной культуры - в погребальной обрядности, керамике, металлических украшениях костюма, которые восходят к ананьинским и гляденовским традициям. Они могут быть объединены в единую этнокультурную общность, связываемую с родственными народами - коми-пермяками и коми-зырянами [23, с. 70-74]. Наибольшую близость к вымским обнаруживают родановские памятники Северного Прикамья, к верхокамским - верхнесысольские (Ужгинский I и II), которые, по мнению их исследователя Н. Н. Чесноковой, оставлены ужгинскими сырьянами [26]. Возможно, население, оставившее ужгинские могильники, входило в то же территориально-племенное объединение, что и верхнекамские коми-пермяки. Сходство с родановскими, по мнению К. С. Королёва, прослеживается в материалах средневычегодского варианта вымской культуры, малонаселённой периферии перми вычегодской [17, с. 33]. В целом территория перми вычегодской в эпоху средневековья была слабо заселённой с редкими поселениями по берегам p. Вычегды и её притоков. В долине р. Выми открыто и исследовано 15 могильников и одно поселение, на Нижней Вычегде известно 4 могильника, из них раскопано два, на Средней Вычегде - поселение, святилище и 5 небольших могильников, на pр. Вашке и Лузе - по одному могильнику, на Сысоле - три. Между тем, как известно, в Прикамье насчитывается более 500 родановских памятников.

Основываясь на современном состоянии источниковой базы и родановской, и вымской культур, представляется, что они были связаны цепочкой взаимосвязанных локальных вариантов в рамках единой общности, более близких в пограничных, смежных районах - на Сысоле и Нижней Вычегде. Как отмечал В. А.Оборин, в ХІ-ХІІ вв. наблюдалась активизация разносторонних этнокультурных, торгово-обменных процессов между населением вымской и родановской культур, внутрирегиональных миграций отдельных групп населения и в северном, и в южном направлениях [21, с. 288], что находит подтверждение в материалах раскопок памятников вымской культуры [21, с. 70-80]. Однако нет никаких свидетельств миграции и носителей родановской культуры в бассейн р. Вычегды, и вымской в Прикамье, что убедительно обосновано в работах Р. Д. Голдиной. Гипотеза о миграции населения перми вычегодской в Прикамье противоречит данным не только археологии, но и лингвистики, палеоантропологии, этнографии, что убедительно доказано в работах В. В. Напольских, Р. Д. Голдиной и многих других исследователей [15, с. 90-92; 12, с. 106-119; 14, с. 102-119].

В заключение пожелаю дорогой, многоуважаемой Римме Дмитриевне творческого долголетия, новых открытий, фундаментальных монографий, талантливых, верных учеников, сохранения так важного для всех нас характерного для неё оптимистического настроя! 


\section{СПИСОК ИСТОЧНИКОВ И ЛИТЕРАТУРЫ}

1. Археология Республики Коми. М.: ДиК, 1994. 758 с.

2. Ашихмина Л. И., Васкул И. О. Памятники ананьинской культурной общности // Археология Республики Коми. М.: ДиК, 1997. С. 314-348.

3. Белавин A. М. Основные этапы этнической истории коренного населения Пермского Прикамья (по данным археологии) // Формирование, историческое взаимодействие и культурные связи финно-угорских народов: материалы III Междунар. конгресса финно-угроведов. Йошкар-Ола: [б. и.], 2004. С. 97-100.

4. Белавин А. М. Этнокультурная ситуация в Пермском Предуралье периода средневековья и нового времени // Пермские финны: археологические культуры и этносы. Сыктывкар: [б. и.], 2007. С. 8-12.

5. Васкул И. О. Памятники гляденовской культурной общности // Археология Республики Коми. М.: ДиК, 1997. С. 349-399.

6. Васкул И. О. Шиховской могильник раннего железного века (первые результаты исследований). Сыктывкар: Коми науч. центр УрО РАН, 2002. 49 с.

7. Голдина Р. Д. Ломоватовская культура в Верхнем Прикамье. Иркутск: Изд-во Иркут. ун-та, 1985.280 с.

8. Голдина Р. Д. Проблемы этнической истории пермских народов в эпоху железа (по археологическим материалам) // Проблемы этногенеза удмуртов. Устинов: [б. и.], 1987. С. 6-37.

9. Голдина Р. Д. Этническая история пермских народов в эпоху железа (по археологическим материалам) // Материалы VI Междунар. конгресса финно-угроведов, т. 1. М.: Наука, 1989. С. 24-26.

10. Голдина Р. Д. Древняя и средневековая история удмуртского народа. Ижевск: Изд. дом «Удмуртский университет», 1999. 464 с.

11.Голдина Р. Д. Мой путь в археологию // Исследовательские традиции в археологии Прикамья. Ижевск: [б. и.], 2002. С. 15-55.

12. Голдина Р. Д. Некоторые замечания относительно формирования теории угорского присутствия в Предуралье в эпоху средневековья // II-й Междунар. мадьярский симпозиум 13-17 авг. 2013 г: сб. науч. тр. Челябинск: [б. и.], 2013. С. 89-110.

13. Голдина Р. Д. О некоторых проблемах средневековой археологии пермян Приуралья // Культурные связи населения европейского Северо-Востока в древности и средневековье. Сыктывкар: [б. и.], 2013. С. $106-119$.

14. Голдина Р. Д. К итогам дискуссии «Угры в Предуралье» // Российская археология. 2016. № 2. С. 102-119.

15. Голдина Р. Д., Напольских В. В. «Угорская эпоха в истории Предуралья»: Научная гипотеза или историографический казус? // Переходные эпохи в археологии. Материалы Всерос. археол. конф. с междунар. участием «ХІХ Уральское археологическое совещание». Сыктывкар: [б. и.], 2013. С. 90-92.

16. Канивец В. И. Печорское Приуралье. Эпоха раннего металла. М.: Наука, 1974. 150 с.

17. Королёв K. С. Предки коми-зырян на Средней Вычегде. Сыктывкар: [б. и.], 2013. 89 с.

18. Королёв К. С., Савельева Э. А. Генезис средневековых культур бассейна Вычегды (II пол. I тыс. н. э. - начало II тыс. н. э.). Сыктывкар: Коми науч. центр УрО АН СССР, 1988. 28 с.

19. Лещинская Н. А., Черных Е. М. Юбилей Риммы Дмитриевны Голдиной // Поволжская археология. 2016. № 3 (17). С. 9-16.

20. Мельникова О. М. Научная археологическая школа Р. Д. Голдиной в Удмуртском университете. Ижевск: [б. и.], 2006. $142 \mathrm{c.}$

21. Оборин В. А. Коми-пермяки // Финно-угры Поволжья и Приуралья в средние века. Ижевск: [б. и.], 1999. C. 255-298.

22. Савельева Э. А. Пермь вычегодская (К вопросу о происхождении народа коми). М.: Наука, 1971. 223 с.

23. Савельева Э. А. Вымско-родановская этнокультурная общность // Археологическое наследие как отражение исторического опыта взаимодействия человека, природы, общества. XIII Бадеровские чтения. Ижевск: [б. и.], 2010. С. 70-74

24. Савельева Э. А. Историко-культурные связи населения бассейна р. Вычегды и Верхнего Прикамья (по материалам вымской и родановской археологической культур) // Вестн. Перм. ун-та. История. 2021. Вып. 1 (52). C. $70-80$.

25.Халиков A. X. Проблемы этногенеза пермских финнов // Материалы VI Междунар. конгр. финно-угроведов. 24 июля 1985 г. Казань: [б. и.], 1985. 16 с.

26. Чеснокова Н. Н. Жизнь на погосте. Предки зырян ужговских в их современном восприятии в археологических источниках // Смерть как феномен культуры. Сыктывкар: СГУ, 1994. С. 166-186.

Поступила в редакцию 25.05.2021

Савельева Элеонора Анатольевна, доктор исторических наук, главный научный сотрудник

отдела археологии

Институт языка, литературы и истории Коми научного центра УрО РАН

167982, Россия, г. Сыктывкар, ул. Коммунистическая, 26

E-mail: eleonorasav@mail.illhkomisc.ru 


\section{E.A. Savelyeva}

\section{THE PERMIAN WORLD IN ANTIQUITY AND THE MIDDLE AGES IN THE WORKS OF R. D. GOLDINA}

DOI: $10.35634 / 2412-9534-2021-31-4-683-693$

In November 2021, Rimma Dmitrievna Goldina, Doctor of History, Professor of the Department of History of Udmurtia, Archaeology and Ethnology, director of the Institute of History and Culture of the Peoples of the Urals of the Udmurt State University, celebrates her anniversary. The article presents the main results of the research of the outstanding Russian scientist on the ethnogenesis of the Permian peoples.

Keywords: archaeology, ethnogenesis, proto-Permian community, Komi-Permian people, Komi-Zyryane people, Udmurts.

\section{REFERENCES}

1. Arheologiya Respubliki Komi [Archeology of the Komi Republic]. Moscow, "DiK” Publ., 1994, 758 p. (In Russian).

2. Ashihmina L. I., Vaskul I. O. Pamyatniki anan'inskoj kul'turnoj obshchnosti [Archaeological site of the Ananyin cultural community]. Arheologiya Respubliki Komi [Archeology of the Komi Republic]. Moscow, "DiK" Publ., 1997, pp. 314-348. (In Russian).

3. Belavin A. M. Osnovnye etapy etnicheskoj istorii korennogo naseleniya Permskogo Prikam'ya (po dannym arheologii) [The main stages of the ethnic history of the indigenous population of the Perm Kama region (according to archeological data)]. Formirovanie, istoricheskoe vzaimodejstvie i kul'turnye svyazifinno-ugorskih narodov. Materialy III Mezhdunarodnogo kongressa finno-ugrovedov [Formation, historical interaction and cultural ties of the Finno-Ugric peoples. Materials of the III International Congress of Finno-Ugric Studies]. Joshkar-Ola, [n. a.], 2004, pp. 97-100. (In Russian).

4. Belavin A. M. Etnokul'turnaya situaciya v Permskom Predural'e perioda srednevekov'ya i novogo vremeni [Ethnocultural situation in the Perm Cis-Urals in Middle Ages and Modern Times]. Permskie finny: arheologicheskie kul'tury i etnosy [Perm Finns: archaeological cultures and ethnic groups]. Syktyvkar, [n. a.], 2007, pp. 8-12. (In Russian).

5. Vaskul I. O. Pamyatniki glyadenovskoj kul'turnoj obshchnosti [Archaeological site of the Glyadenov cultural community]. Arheologiya Respubliki Komi [Archeology of the Komi Republic]. Moscow, "DiK” Publ., 1997, pp. 349399. (In Russian).

6. Vaskul I. O. Shihovskoj mogil'nik rannego zheleznogo veka (pervye rezul'taty issledovanij) [Shikhovsky burial ground of the early Iron Age (first results of research)]. Syktyvkar, Ed. of the Komi scientific Center of the Ural Branch of RAS, 2002, 49 p. (In Russian).

7. Goldina R. D. Lomovatovskaya kul'tura v Verhnem Prikam'e [Lomovatovskaya culture in the Upper Kama region]. Irkutsk, Irkutsk State University Press, 1985, 280 p. (In Russian).

8. Goldina R. D. Problemy etnicheskoj istorii permskih narodov v epohu zheleza (po arheologicheskim materialam) [Problems of the Ethnic History of the Permian Peoples in the Iron Age (Based on Archaeological Materials)]. Problemy etnogeneza udmurtov [Problems of Udmurt ethnogenesis]. Ustinov, [n. a.], 1987, pp. 6-37. (In Russian).

9. Goldina R. D. Etnicheskaya istoriya permskih narodov v epohu zheleza (po arheologicheskim materialam) [Ethnic history of the Permian peoples in the Iron Age (based on archaeological materials)]. Materialy VI Mezhdunarodnogo kongressa finno-ugrovedov, t. 1 [Materials of the VI International Congress of Finno-Ugric Studies, vol. 1]. Moscow, "Nauka" Publ., 1989, pp. 24-26. (In Russian).

10. Goldina R. D. Drevnyaya i srednevekovaya istoriya udmurtskogo naroda [Ancient and medieval history of the Udmurt people]. Izhevsk, "Udmurt University” Publ., 1999, 464 p. (In Russian).

11. Goldina R. D. Moj put' v arheologiyu [My path to archeology]. Issledovatel'skie tradicii v arheologii Prikam'ya [Research traditions in the archeology of the Kama region]. Izhevsk, [n. a.], pp. 15-55. (In Russian).

12. Goldina R. D. Nekotorye zamechaniya otnositel'no formirovaniya teorii ugorskogo prisutstviya v Predural'e v epohu srednevekov'ya [Some remarks on the formation of the theory of the Ugric presence in the Cis-Urals in the Middle Ages]. II-j Mezhdunarodnyj mad'yarskij simpozium 13-17 avgusta 2013 g. Sbornik nauchnyh trudov [II International Magyar Symposium, August 13-17, 2013. Collection of scientific papers]. Chelyabinsk, [n. a.], 2013, pp. 89-110. (In Russian).

13. Goldina R. D. O nekotoryh problemah srednevekovoj arheologii permyan Priural'ya [On some problems of medieval archeology of the Permians of the Urals]. Kul'turnye svyazi naseleniya evropejskogo Severo-Vostoka v drevnosti i srednevekov'e [Cultural ties of the population of the European North-East in the ancient and medieval times]. Syktyvkar, [n. a.], 2013, pp. 106-119. (In Russian).

14. Goldina R. D. K itogam diskussii "Ugry v Predural'e" [To the results of the discussion "Ugrians in the Urals"]. Rossijskaya arheologiya [Russian archeology], 2016, no. 2, pp. 102-119. (In Russian). 
15. Goldina R. D., Napol'skih V. V. "Ugorskaya epohav istorii Predural'ya": Nauchnaya gipoteza ili istoriograficheskij kazus? ["Ugrian era in the history of the Urals": Scientific hypothesis or historiographic incident?]. Perekhodnye epohi v arheologii. Materialy Vserossijskoj arheologicheskoj konferencii s mezhdunarodnym uchastiem "XIX Ural'skoe arheologicheskoe soveshchanie" [Transitional epochs in archeology (Materials of the All-Russian archaeological conference with international participation "19th Ural archaeological meeting"]. Syktyvkar, [n. a.], 2013, pp. 90-92. (In Russian).

16. Kanivec V. I. Pechorskoe Priural'e. Epoha rannego metalla [Pechora Urals. The era of early metal]. Moscow, "Nauka" Publ., 1974, 150 p. (In Russian).

17. Korolev K. S. Predki komi-zyryan na Srednej Vychegde [Ancestors of the Komi-Zyryan on Average Vychegda]. Syktyvkar, [n. a.], 2013, 89 p. (In Russian).

18. Korolev K. S., Savel'eva E. A. Genezis srednevekovyh kul'tur bassejna Vychegdy (II pol. I tys. n. e. — nachalo II tys. n. e.) [The genesis of medieval cultures of the Vychegda basin (II half of the 1st millennium AD - the beginning of the 2nd millennium AD)]. Syktyvkar, Ed. of the Komi scientific Center of the Ural Branch of RAS, 1988, 28 p. (In Russian).

19. Leshchinskaya N. A., Chernyh E. M. Yubilej Rimmy Dmitrievny Goldinoj [Anniversary of Rimma Dmitrievna Goldina]. Povolzhskaya arheologiya [Volga archeology], 2016, no. 3 (17), pp. 9-16. (In Russian).

20. Mel'nikova O. M. Nauchnaya arheologicheskaya shkola R. D. Goldinoj v Udmurtskom universitete [Scientific archaeological school of R. D. Goldina at the Udmurt University]. Izhevsk, [n. a.], 2006, 142 p. (In Russian).

21. Oborin V. A. Komi-permyaki [Komi-Perm]. Finno-ugry Povolzh'ya i Priural'ya v srednie veka [Finno-Ugrians of the Volga and Urals in the Middle Ages]. Izhevsk, [n. a.], 1999, pp. 255-298. (In Russian).

22. Savel'eva E. A. Perm' vychegodskaya (K voprosu o proiskhozhdenii naroda komi) [Vychegodskaya Perm (On the origin of the Komi people)]. Moscow, "Nauka" Publ., 1971, 223 p. (In Russian).

23. Savel'eva E. A. Vymsko-rodanovskaya etnokul'turnaya obshchnost' [Vymsko-Rodanovskaya ethnocultural community]. Arheologicheskoe nasledie kak otrazhenie istoricheskogo opyta vzimodejstviya cheloveka, prirody, obshchestva. XIII Baderovskie chteniya [Archaeological heritage as a reflection of the historical experience of interaction between man, nature, society. 13th Bader Readings]. Izhevsk, [n. a.], 2010, pp. 70-74. (In Russian).

24. Savel'eva E. A. Istoriko-ku'turnye svyazi naseleniya bassejna r. Vychegdy i Verhnego Prikam'ya (po materialam vymskoj i rodanovskoj arheologicheskoj kul'tur) [Historical and cultural ties of the population of the river basin Vychegda and the Upper Kama region (based on materials from the Vymskaya and Rodanovskaya archaeological cultures)]. Vestnik Permskogo universiteta. Istoriya [Bulletin of the Perm University. History], 2021, issue 1 (52), pp. 70-80. (In Russian).

25. Halikov A. H. Problemy etnogeneza permskih finnov [Ethnogenesis problems of the Perm Finns]. Materialy VI Mezhdunarodnogo kongressa finno-ugrovedov (doklad na mezhsekcionnom zasedanii po probleme "Etnogenez permskih finnov" [Materials of the VI International Congress of Finno-Ugric Studies (report at the intersectional meeting on the problem "Ethnogenesis of the Permian Finns"]. Kazan, [n. a.], 1985, 16 p. (In Russian).

26. Chesnokova $N$. N. Zhizn' na pogoste. Predki zyryan uzhgovskihv ih sovremennom vospriyatiiv arheologicheskih istochnikah [Life in the churchyard. The ancestors of the Uzhgovsky Zyryans in their modern perception and in archaeological sources]. Smert' kak fenomen kul'tury [Death as a cultural phenomenon]. Syktyvkar, Syktyvkar State University Press, 1994, pp. 166-186. (In Russian).

Received 25.05.2021

Savelyeva E. A., Doctor of History, Chief Researcher of the Department of Archeology

Institute of Language, Literature and History of the Komi Scientific Center of the Ural Branch of the RAS

Kommunisticheskaya st., 26, Syktyvkar, Russia, 167982

E-mail: eleonorasav@mail.illhkomisc.ru 